$\begin{array}{lll}\text { Submission: 24/Oct/2016; } & 1^{\text {st }} \text { round notif.: 20/Dec/2016; } & \text { New version: 30/Jul/2017; } \\ \text { Camera ready: 07/Dec/2017; } & \text { Edition review: 13/Mar/2018; } & \text { Available online: 17/Mar/2018; }\end{array}$

\title{
Um Estudo sobre a Aprendizagem de Função Exponencial no Ambiente Computacional
}

\section{Title: A Study on the Exponential Function Learning in the computing environment}

Mariana Silva Mendonça

Universidade Estadual de Santa Cruz

Programa de Pós-Graduação em Educação Matemática

marianasilvamendonca@gmail.com

\author{
Rogério Fernando Pires \\ Universidade Estadual de Santa Cruz \\ Programa de Pós-Graduação em Educação Matemática \\ rfpires25@bol.com.br
}

\begin{abstract}
Resumo
O software GeoGebra possui uma interface que possibilita a exploração simultânea de dois tipos de registros de representação de uma função, o algébrico e o gráfico. Essa possibilidade de explorar dois tipos de registros vai ao encontro da ideia da Teoria dos Registros de Representação Semiótica (TRRS), a manipulação e a coordenação de ao menos duas representações de um mesmo objeto matemático, defendida por Raymond Duval. Assim, o presente artigo tem por objetivo compreender como a utilização do software GeoGebra pode auxiliar alunos do Ensino Médio na aprendizagem de função exponencial por meio da mobilização, manipulação e coordenação de representações semióticas durante uma atividade interventiva. Para tanto, foi aplicado um instrumento de intervenção composto por sete atividades que contemplou o estudo da função exponencial fundamentado na TRRS. O instrumento foi aplicado a um grupo de alunos do $1 .^{\circ}$ ano do Ensino Médio de um colégio estadual situado no extremo sul do Estado da Bahia. A análise desse instrumento foi de natureza qualitativa e revelou que o software GeoGebra pode auxiliar os alunos na aprendizagem de função exponencial, uma vez que as respostas dadas pelos alunos nas atividades indicaram que a maior parte deles respondeu de maneira assertiva, construindo o conhecimento sobre o objeto matemático em estudo por meio da mobilização, manipulação e coordenação das representações e exploração de propriedades da função estudada.
\end{abstract}

Palavras-Chave: GeoGebra; Teoria dos Registros de Representação Semiótica; Função exponencial.

\begin{abstract}
GeoGebra software has an interface that enables the simultaneous operation of two types of representation of function records, algebraic and graphic. This possibility of exploring two types of records matches the idea of the Theory of Semiotics Representation Registers (TRRS), handling and coordination of at least two representations of the same mathematical object, defended by Raymond Duval. Thus, this article aims to understand how the use of GeoGebra software can help high school students in learning exponential function through mobilization, manipulation and coordination of semiotic representations during an interventional activity. Therefore, an intervention instrument composed of seven activities which included the study of the exponential function based on TRRS. The instrument was administered to a group of students first year of high school from public school located in the extreme south of Bahia. The analysis of this instrument was qualitative and revealed that the GeoGebra software can assist students in learning exponential function, since the answers given by the students in the activities indicated that most of the students responded assertively, building knowledge about the mathematical object under study through mobilization, manipulation and coordination of representations and exploitation properties of studied function.
\end{abstract}

Keywords: GeoGebra; Theory of Semiotics Representation Registers; Exponential Function.

Cite as: Mendonça, M. S., \& Pires, R. F. (2018). A Study on the Exponential Function Learning in the computing environment (Um Estudo sobre a Aprendizagem de Função Exponencial no Ambiente Computacional). Brazilian Journal of Computers in Education (Revista Brasileira de Informática na Educação - RBIE), 26(2), 01-28. DOI: 10.5753/RBIE.2018.26.02.1 


\section{Introdução}

O presente artigo objetivou compreender como a utilização do software GeoGebra pode auxiliar alunos do Ensino Médio na aprendizagem de função exponencial por meio da mobilização, manipulação e coordenação de representações semióticas durante uma atividade interventiva. Esse artigo é um recorte de um estudo de mestrado, o qual já teve resultados parciais publicados ${ }^{1}$.

As dificuldades dos alunos de estudar função já foi tema de alguns estudos científicos. Pires (2014, p. 22) ressalta em sua tese de doutorado essas dificuldades ao apresentar alguns resultados de macroavaliações, sinalizando que "o fraco desempenho dos estudantes nas questões que envolviam tal conceito no Enem 2009 (Exame Nacional do Ensino Médio), no Saresp 2009 (Sistema de Avaliação do Estado de São Paulo) e na ANEB 2009 (Avaliação Nacional da Educação Básica)”. Sierpinska (1992) e Sfard (1992) também relatam a dificuldade que frequentemente os alunos apresentam ao trabalharem com o conceito de função.

Entre essas dificuldade de trabalhar com a função exponencial, destacamos uma, evidenciada a partir dos resultados apresentados em uma das questões da matriz do Sistema de Avaliação da Educação Básica (SAEB) do ano 2011, como podemos observar na Figura 1.

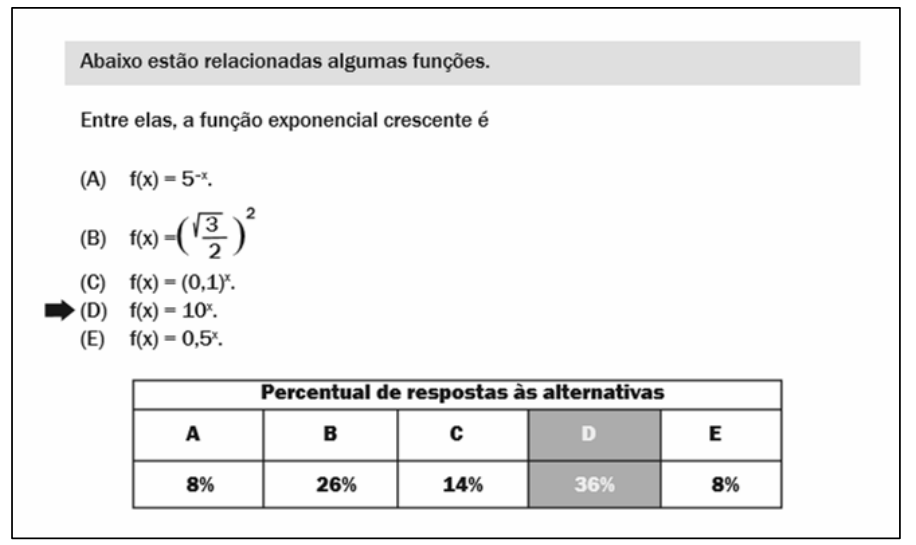

Figura 1: Imagem de uma das questões abordadas na matriz de referência do SAEB do ano 2011.

Como é possível observar, a questão solicitava que os alunos indicassem qual das representações algébricas apresentadas nas alternativas refere-se a uma função exponencial crescente. Apenas 36\% dos alunos concluintes do Ensino Médio, no ano em que foram avaliados, responderam corretamente a questão.

É possível observar, nessa questão, que a maior parte dos alunos desconhece as unidades simbólicas significativas que compõem o registro algébrico de uma função exponencial (que são as unidades de sentido desse tipo de registro, como o fato de a variável estar no expoente e a condição da base da potência presente na representação algébrica da função exponencial), mesmo sendo uma tarefa simples, como afirma Duval, "a discriminação das unidades significativas próprias a uma expressão algébrica é relativamente evidente” (2011a, p. 99).

É possível observar, ainda, que o relatório do SAEB também trata sobre esse assunto, que $26 \%$ dos alunos marcaram como opção de resposta a alternativa $b$, que nem sequer representa uma função exponencial, revelando a dificuldade que eles têm em simplesmente de reconhecer uma função exponencial, quando ela está representada no registro algébrico.

\footnotetext{
${ }^{1}$ Trabalho intitulado "Registro de Representação Semiótica e Tecnologias Digitais na Aprendizagem de Função Exponencial".
} 
As dificuldades dos alunos com o estudo de função exponencial estendem-se em relacionar a representação do registro gráfico à do registro algébrico desse tipo de função, conforme é possível observar nos estudos de Duval (2011b). Nesse contexto, o GeoGebra pode auxiliar os alunos na aprendizagem desse conteúdo, visto que ele permite explorar o registro algébrico e o gráfico em uma mesma interface.

O estudo da função exponencial faz-se relevante, pois ele é fundamental para a formação dos alunos, em especial por ajudá-los a compreender alguns fenômenos presentes na sociedade, por exemplo, o crescimento da população de uma determinada região, a disseminação de uma doença, as alterações no mercado financeiro, entre outros, e isso é pontuado nos Parâmetros Curriculares Nacionais do Ensino Médio (PCNEM)(Brasil, 1999), quando orientam que esse conteúdo exerce importante papel no estudo do comportamento de alguns fenômenos, tanto no cotidiano quanto em outras áreas do conhecimento.

Uma das funções que nos permitem modelar uma série de fenômenos presentes em nosso dia a dia é a função exponencial. Considerando as dificuldades que os alunos do $10^{\circ}$ ano do Ensino Médio apresentam ao estudar esse conteúdo e a facilidade com que, de maneira geral, têm de lidar com algumas Tecnologias Digitais, ${ }^{2}$, como o computador e o celular, fizeram com que o presente estudo fosse relevante, pois os auxiliou em seu processo de aprendizagem. Além disso, os PCNEM indicam um redirecionamento do ensino da Matemática de modo a reconsiderar o impacto das tecnologias na sociedade.

Diante um cenário de dificuldades quanto ao processo de ensino e aprendizagem de função exponencial e a importância que esse conteúdo tem no campo da matemática, algumas pesquisas têm sido realizadas. Santos (2011), em sua pesquisa de mestrado, elaborou e aplicou uma sequência didática em que o objeto matemático era função logarítmica e, para tanto, ela contou com o auxílio do software GeoGebra. No tocante aos procedimentos metodológicos, a sequência didática foi composta por questões do Caderno do Professor de Matemática da $1 .^{\text {a }}$ série do Ensino Médio, volume 3, do Estado de São Paulo, do ano de 2009, que foram adaptadas para esta pesquisa. As questões foram agrupadas em quatro seções, a saber: Consolidação da ideia de potência; Explorar o conceito de função exponencial; Explorar o conceito de logaritmos e funções inversas. Apesar de o foco desse estudo ser a função logarítmica, a autora achou pertinente manter esses conteúdos conforme sugerido pelo caderno.

Como benefícios da utilização do software, a autora destacou que os alunos participantes da pesquisa indicaram que o GeoGebra contribuiu com a visualização e com a compreensão da função estudada. Essa pesquisa se aproximou da nossa por ter investigado, também, a função exponencial (mesmo não sendo o objeto principal da pesquisa) e por ter utilizado o GeoGebra.

Oliveira (2015) realizou um estudo, no qual investigou as principais propriedades da função exponencial, no que tange à coordenação entre os registros algébricos e gráficos dessa função. Para tanto, o autor pesquisou os subconjuntos dos números reais e ao final do trabalho apresentou algumas aplicações da referida função, que podem contribuir com o trabalho do professor da Educação Básica. Assim como a nossa pesquisa, essa estudou propriedades da função exponencial, aproximando-se do que foi feito por nós, entretanto afastamos dessa pesquisa ao aplicar uma proposta em uma turma da Educação Básica.

Silva (2012), em sua pesquisa de mestrado, realizou um estudo sobre função exponencial e logarítmica e, a partir desse estudo, elaborou e aplicou uma sequência de ensino em que foram trabalhados esses dois conteúdos. A sequência foi fundamentada pela Teoria dos Campos Conceituais de Vergnaud e pela Teoria dos Registros de Representação Semiótica, proposta do Raymond Duval. Nessa sequência o pesquisador lançou mão de situações-problema e investigou a relação entre as grandezas envolvidas nas funções. $\mathrm{O}$ autor destacou resultados positivos com a

\footnotetext{
${ }^{2}$ Termo empregado na quarta fase da história das tecnologias na Educação Matemática, como indicam Borba, Silva e Gadanidis [2].
} 
aplicação dessa sequência. A nossa investigação, assim como a de Silva, elaborou e aplicou uma sequência de ensino que propõe o trabalho com função exponencial tomando como fundamentação teórica a TRRS, entretanto as direcionamos a mobilização, manipulação e coordenação entre os diferentes registros dessa função, em especial o registro algébrico e gráfico.

Monzon e Gravina (2013), publicaram um trabalho no qual apresentam os resultados da experiência vivenciada por elas, ao trabalharem a introdução das funções de variável complexa por meio do produto educacional. A pesquisa foi planejada com o intuito de validar o produto anteriormente elaborado, que não havia sido explorado em sala de aula, a experimentação foi realizada em uma turma do $3 .^{\circ}$ ano do Ensino Médio noturno de uma escola da rede estadual do Rio Grande do Sul no ano de 2011. Participaram vinte e seis alunos e as atividades tiveram duração de doze horas, distribuídas em onze encontros ao longo de um mês.

$\mathrm{O}$ produto educacional trata-se de um site web e, para a construção, as autoras se fundamentaram na Teoria dos Registros de Representação Semiótica. Foram utilizadas também algumas tecnologias educacionais na construção do site web, como o software GeoGebra, que possibilitou dar dinamismo e animações interativas aos conteúdos acompanhados de explicações e de questões que podiam ser exploradas pelos usuários. Para as autoras, as animações interativas construídas no software GeoGebra foram o diferencial do site web, sendo um recurso bastante explorado pelas pesquisadoras. Elas também destacam algumas das possibilidades do software GeoGebra, entre elas a facilidade da exploração algébrica e gráfica simultaneamente. A exploração permitiu as autoras constatarem que o produto educacional é adequado, o que nos chama a atenção para as potencialidades do software GeoGebra no processo de aprendizagem de função exponencial, em especial na exploração do registro gráfico e algébrico e na conversão entre esses registros.

Pesquisas como essas nos indica a necessidade de investigar o processo de ensino e aprendizagem de função exponencial, de modo a contribuir com o cenário no qual ela se fez presente no contexto de sala de aula. Diante disso, elaboramos um proposta aliando a TRRS ao software GeoGebra. No que se refere à escolha do software, fizemos essa opção pois ele permite que o estudo das relações entre os registros algébrico e gráfico seja mais expressivo, uma vez que permite um volume maior de construções gráficas e, ainda, por ser um software livre, que possibilita a construção de figuras geométricas em duas dimensões, bem como a sua manipulação. Ao escolher esse software, esperamos que ele auxilie os alunos no processo de aprendizagem, em virtude de possuir uma interface gráfica simples, além de possibilitar a relação entre as representações algébrica e gráfica de uma função e a manipulação dessas representações pelos próprios alunos.

Diante desse cenário, buscamos respostas para a seguinte indagação: Como a utilização do software GeoGebra pode auxiliar alunos do Ensino Médio na aprendizagem de função exponencial por meio da mobilização, manipulação e coordenação de representações semióticas durante uma atividade interventiva?

Para tanto, o presente artigo segue estruturado em sessões. Na primeira delas, intitulada Considerações sobre a TRRS e o uso do GeoGebra no estudo de Matemática, são apresentados conceitos da teoria (TRRS) que sustentou a investigação, além de algumas considerações a respeito da tecnologia utilizada.

$\mathrm{Na}$ sessão seguinte, Proposta de intervenção, é apresentado o que foi proposto como intervenção para o estudo da definição da função exponencial. Na sequência, é feita a análise da intervenção, em que exploramos algumas respostas apresentadas pelos sujeitos dessa pesquisa. E, por fim, são indicados alguns resultados e reflexões dessa pesquisa.

\section{Considerações sobre a TRRS e o uso do GeoGebra no estudo de Matemática}


As questões relacionadas ao conhecimento humano estão diretamente ligadas ao objeto de conhecimento e suas representações. Muitas vezes tidas como "imitações" do objeto, as representações são confundidas com o próprio objeto, gerando o que aqui chamamos de "dualidade entre objeto e representação". Assim, em Matemática é muito comum ao se perguntar aos estudantes o que é " $f: \mathbb{R} \rightarrow \mathbb{R}, f(x)=\left(\frac{2}{3}\right)^{x}$ " e, ele responder que é uma função e não a representação algébrica de uma função. Esse, é um típico exemplo de confusão da representação com o objeto matemático, ou seja, é tomar a representação no lugar do próprio objeto.

A Teoria dos Registros de Representação Semiótica vem a ajudar a entender como se dá o processo de compreensão em Matemática. Nessa direção, Duval (2011 a) afirma que os objetos matemáticos só são acessíveis por meio de suas representações, destacando, assim, a importância da representação para que possamos ter acesso a esses objetos. Nesse sentido, ele assinala que:

\begin{abstract}
[...] contrariamente ao que sempre se postula no ensino da Matemática, a discriminação das unidades de sentido pertinentes nas diferentes representações não é a consequência da aquisição de conceitos, mas condição preliminar dessa aquisição. Analogamente, a escolha de uma "boa" representação, ou mesmo a multiplicação de representações, são apenas ajudas enganosas. Pois as "boas" representações não podem ser associadas aos objetos matemáticos que elas representam, porque esses não são acessíveis direta ou empiricamente. A única via de acesso possível aos objetos empiricamente não acessíveis passa por colocar em correspondência representações semióticas diferentes (2011a, p. 49).
\end{abstract}

Isso explica a importância de não se tomar os objetos pelas suas representações, mas sim reconhecer o objeto em suas múltiplas representações, pois é o contato com essa diversidade que tornará o indivíduo habilidoso na mobilização das diferentes representações dos objetos matemáticos.

Portanto, podemos dizer que, assim como os demais objetos, a função exponencial só pode ser acessada por meio de suas representações. Por exemplo, quando um aluno constrói o gráfico que representa a função exponencial ou elabora uma tabela com valores que descrevem uma relação funcional apresentando características exponenciais, ele está trabalhando as representações desse objeto.

Nesse ínterim, Duval sustenta que "o conhecimento começa quando não adotamos mais a representação do objeto no lugar do próprio objeto" (2011a, p. 16-17) e, para o autor, uma das formas "para não confundir o objeto matemático e sua representação é dispor de uma segunda representação cujo conteúdo será diferente da primeira" (2011a, p. 48).

Duval ainda enfatiza, "a compreensão em matemática supõe a coordenação de ao menos dois registros de representação semiótica" (2011a, p. 15).

Essa passagem nos chama a atenção para o fato de os objetos matemáticos disporem de diferentes representações e a importância da exploração dos diversos tipos de representação para uma melhor compreensão dos conteúdos em Matemática. Assim, esses estudos não podem ser restritos a um tipo de registro, e a aprendizagem só acontecerá se o indivíduo conseguir transitar pelas diferentes representações de um mesmo objeto.

Para que um conhecimento ou um saber matemático possa ser colocado em funcionamento, é necessário que o individuo manipule não somente um registro de representação, mas, pelo menos dois e que saiba coordenar esses registros, pois a articulação entre eles e a capacidade de fazer a troca entre a todo instante é que determina quão indivíduo é habilidoso na realização das tarefas matemáticas.

As diferentes representações podem ser alcançadas pelas transformações, que podem permanecer no mesmo sistema de registro, que é denominado tratamento, ou mudar de sistema, que é a conversão. Como exemplo de tratamento, podemos citar o caso em que o indivíduo está diante da representação algébrica de uma função e a reescreve de outra maneira como, por 
exemplo, quando se transforma a expressão $f(x)=3^{x}$ em $f(x)=\left(\frac{1}{3}\right)^{-x}$, ambas expressões são representações algébricas da mesma função. Já a conversão ocorrer quando, a partir da representação algébrica de uma função, o indivíduo constrói a representação gráfica.

Vale ainda destacar que as regras de conversão não são as mesmas segundo o sentido no qual está sendo realizada a mudança de registro. Uma conversão do registro algébrico para o registro gráfico, por exemplo, requer do indivíduo a mobilização de estratégias completamente diferentes das requeridas na conversão no sentido contrário. Sendo assim, nosso discurso vai ao encontro as ideias de Duval (2003), quando este afirma que a originalidade da atividade matemática está na mobilização simultânea de, pelo menos, dois registros de representação de um mesmo objeto matemático e, na possibilidade de trocar a todo momento de registro.

Ainda nessa direção Duval destaca que

[...] a ausência de coordenação entre diferentes registros cria muito frequentemente uma deficiência para a aprendizagens conceituais. Inversamente, uma aprendizagem especificamente centrada na mudança de e na coordenação de diferentes registros de representação produz efeitos espetaculares nas macro tarefas de produção e de compreensão. (2009, p. 63).

Diante disso, a nossa intervenção de ensino foi pensada para contemplar as transformações entre os registros da função exponencial, em especial a conversão entre os registros algébrico e gráfico. Essas transformações contaram com o auxílio do GeoGebra, que, com a análise dos resultados, evidencia ter contribuído com a aprendizagem da função exponencial.

De acordo com Duval (2011a), a mobilização e a coordenação de diferentes representações de um mesmo objeto matemático é que darão ao indivíduo condições para que ele possa compreender, de maneira ampla, o conceito que está sendo estudado. No caso da função exponencial, a articulação entre as representações algébrica e gráfica pode possibilitar ao aluno a descoberta de algumas propriedades fundamentais para a compreensão desse conceito.

Nessa perspectiva, o software GeoGebra pode contribuir com a compreensão de função exponencial, bem como auxiliar na conversão entre os registros algébrico e gráfico. O GeoGebra foi escolhido por ser um software de Matemática dinâmica gratuito, de fácil manipulação (para o que pretendíamos utilizar) e, principalmente, por contemplar em uma mesma interface o registro algébrico e gráfico, como é possível ver na Figura 2, bem como pelo dinamismo que ele oferece, possibilitando que o aluno veja em uma mesma interface o registro algébrico e gráfico da função estudada.

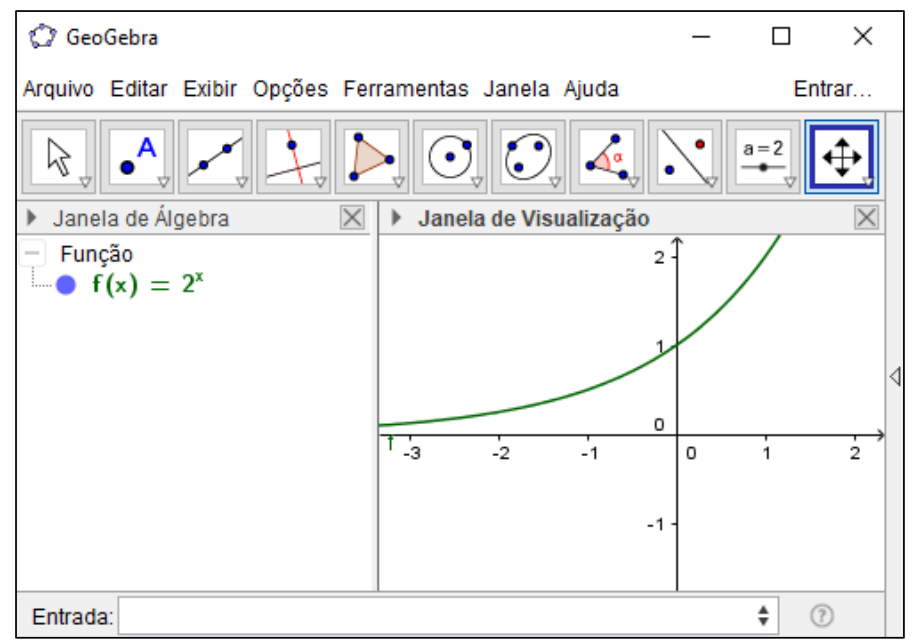

Figura 2: Interface do software GeoGebra com o registro de representação algébrico e gráfico da função $\mathrm{f}(\mathrm{x})=2^{x}$. 
O uso do GeoGebra no espaço escolar pode proporcionar experimentações, visto que, com esse software, as tarefas são realizadas de maneira mais rápida do que no ambiente lápis e papel, permitindo a realização de um volume maior de atividades, o que possibilita ao aluno destinar um tempo maior para estabelecer relações entre as diferentes representações de uma mesma função, propiciando uma melhor apreensão dos conceitos abordados. Além disso, o caráter dinâmico do software pode ocasionar a visualização de propriedades que, no ambiente lápis e papel, podem ser mais difíceis de ser observadas como os movimentos de translação.

Nesse sentido, Borba e Penteado afirmam que "é difícil a geração de diversos gráficos num ambiente em que predomina o uso de lápis e papel" (2003, p. 32), e isso pode, de certa forma, limitar a aprendizagem dos alunos, uma vez que diversas propriedades podem deixar de ser exploradas por conta do tempo demandado para a construção de gráficos no ambiente lápis e papel. Corroborando com Borba e Penteado no que tange às múltiplas gerações de registros com o auxílio das tecnologias, Duval afirma que "obtemos, imediatamente, muito mais que tudo o que poderíamos obter à mão livre após, talvez, vários dias de escrita e cálculos ou construções de figuras" (2011a, p. 137).

Ao permitir as experimentações, o software GeoGebra abre espaço para que possa explorar a conversão da representação algébrica para a gráfica e vice-versa, facultando a compreensão do que cada elemento em um tipo de representação corresponde no outro. Quanto às possibilidades de trabalhar a conversão do registro gráfico para o algébrico, o software GeoGebra se mostra ainda mais interessante, pois, como afirma Duval, é "a passagem do registro gráfico para o algébrico que traz problemas para os alunos" (2011b, p. 97), uma vez que, com o uso do GeoGebra, o conteúdo é explorado por meio da abordagem de interpretação global de propriedades figurais.

Ao escolhermos o uso desse software nessa pesquisa, nosso objetivo era que ele possibilitasse aos alunos explorar as relações entre as variáveis visuais pertinentes da representação gráfica e as unidades simbólicas significativas da representação algébrica, que são as informações matematicamente pertinentes de cada tipo de registro. Isso é fundamental para que os alunos consigam perceber as implicações das unidades simbólicas significativas nas variáveis visuais pertinentes. Nesse sentido, Duval sustenta que:

“[...] não pode haver utilização correta das representações gráficas cartesianas sem a discriminação explícita das variáveis visuais pertinentes e sem uma correspondência sistematicamente estabelecida entre os valores dessas variáveis e as unidades significativas da expressão algébrica" (2011a, p. 104).

Desse modo, é importante que os elementos característicos do registro gráfico da função exponencial sejam investigados e que essas características sejam associadas aos elementos do registro algébrico, pois a associação das variáveis visuais pertinentes às unidades simbólicas significativas permite que a conversão entre as representações algébrica e gráfica seja qualitativa, ou seja, possibilita que o indivíduo perceba quais as implicações na representação gráfica das alterações na representação algébrica e vice-versa. Com base no que foi exposto até aqui, elaboramos um instrumento de intervenção.

\section{Proposta de intervenção}

Para que o objetivo da pesquisa fosse alcançado, elaboramos e aplicamos um instrumento de intervenção composto por sete atividades. Com ele, nosso objetivo era explorar elementos e propriedades relacionados à definição de função exponencial que consideramos importantes no estudo desse conteúdo, pois a definição é fundamental para que os alunos compreendam o conceito desse objeto matemático e sejam capazes de identificá-lo ao se depararem com situações em que ele aparece. 
O instrumento foi planejado considerando os direcionamentos propostos pela TRRS e essa teoria influenciou a elaboração das atividades, por exemplo, a exploração de, ao menos, dois tipos de registros de representação do objeto matemático em questão, pois, como diz Duval, "os registros são ferramentas para avaliar a pertinência cognitiva de sequência de atividades, isto é, sua adequação às condições necessárias para desenvolver a compreensão" (2011a, p. 141).

Exploramos, também, atividades que exigem as transformações do objeto de estudo, uma vez que o mesmo autor aponta que "o que é matematicamente essencial em uma representação semiótica são as transformações que se podem fazer, e não a própria representação" (2011a, p. $68)$.

A Figura 3 apresenta a primeira atividade do instrumento de intervenção.

\begin{tabular}{|c|c|c|}
\hline \multicolumn{3}{|c|}{$\begin{array}{l}\text { Atividade 01: Uma imobiliária está vendendo alguns terrenos em um loteamento da } \\
\text { cidade. Na propaganda, eles dizem que o imóvel terá uma valorização de } 8 \% \text { ao } \\
\text { ano. Sabendo que cada terreno custa, hoje, } R \$ 14000,00 \text {, determine o valor do } \\
\text { imóvel com o passar do tempo preenchendo o quadro a seguir. Para o } \\
\text { preenchimento dos campos referentes às expressões, utilize os dados do ano } \\
\text { anterior e coloque os termos comuns em evidência. }\end{array}$} \\
\hline Tempo & Expressão & $\begin{array}{c}\begin{array}{l}\text { Valor do terreno em } \\
\text { Reais }\end{array} \\
\end{array}$ \\
\hline Hoje & 14000 & 14000 \\
\hline Após 1 ano & $\begin{array}{l}14000+14000 \times 0,08 \\
=14000 \times(1+0,08) \\
=14000 \times 1,08\end{array}$ & 15120 \\
\hline Após 2 anos & $\begin{aligned} 14000 \times 1,08 & +14000 \times 1,08 \times 0,08 \\
= & 14000 \times 1,08(1+0,08) \\
& =14000 \times 1,08^{2}\end{aligned}$ & 16329,60 \\
\hline \multicolumn{3}{|l|}{ Após 3 anos } \\
\hline Após 4 anos & & \\
\hline
\end{tabular}

Figura 3: $1 .^{\mathrm{a}}$ atividade extraída do instrumento de intervenção.

Essa atividade se trata de uma situação-problema expressa em língua materna, a qual pode ser modelada por uma função exponencial, e a atividade explora o registro numérico e algébrico. $\mathrm{O}$ objetivo era observar a relação de dependência entre as grandezas envolvidas e verificar se após a realização de alguns tratamentos aritméticos os alunos conseguiriam realizar a generalização da situação apresentada.

Para responder, os alunos devem reconhecer as unidades de sentido, isto é, os dados ou informações matematicamente pertinentes, expressos em língua materna, e delinear as transformações dessas unidades, inicialmente, da língua materna para o registro numérico. Em outras palavras, realizar uma conversão da língua materna para o registro numérico, de modo que o preenchimento permita chegar na construção do registro algébrico para responder o último item da atividade.

$\mathrm{Na}$ Figura 4 é apresentada a atividade 2. 


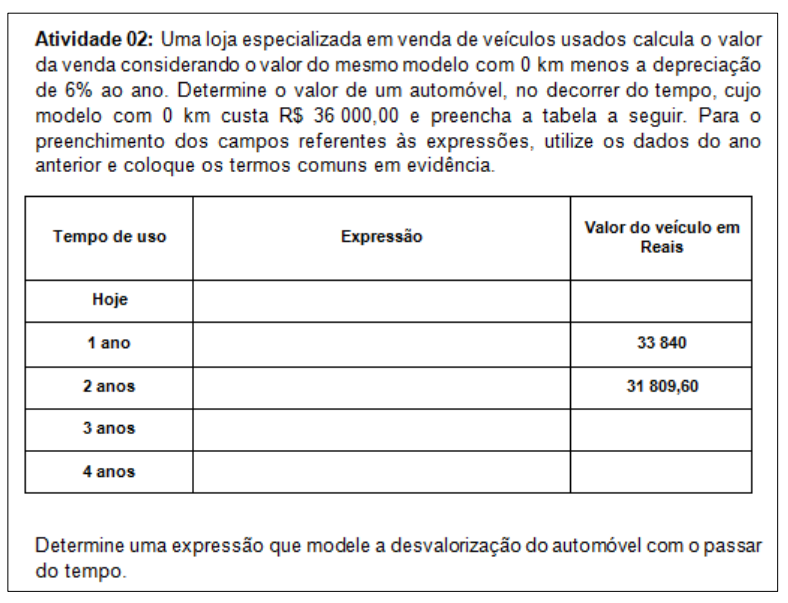

Figura 4: 2. ${ }^{\mathrm{a}}$ atividade extraída do instrumento de intervenção.

O objetivo dessa atividade foi explorar a relação de dependência entre as grandezas envolvidas e verificar se depois da realização de alguns tratamentos aritméticos os alunos conseguem generalizar a situação apresentada de modo a chegarem na expressão $y=5000 \cdot 0,95^{x}$.

Essa segunda atividade foi semelhante à anterior, entretanto a situação-problema evidencia um comportamento decrescente da função que a modela. Ela foi pensada para estimular, com a atividade anterior, o estudo das informações matematicamente pertinentes do registro algébrico da função estudada.

A Figura 5, a seguir, apresenta a atividade 3 que compõe o instrumento de intervenção.

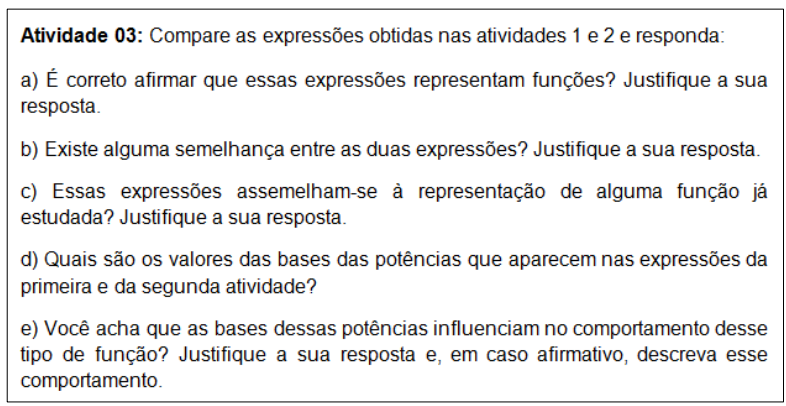

Figura 5: $3 .^{\mathrm{a}}$ atividade extraída do instrumento de intervenção.

A terceira atividade propôs reflexões acerca das expressões obtidas nas duas primeiras atividades. O item (a) teve o objetivo de explorar o conceito de função e, com esse item, o propósito era verificar se os alunos percebiam se as expressões encontradas anteriormente são funções expressas no registro algébrico. Para responder a esse item, os alunos deveriam identificar as unidades de sentido nas expressões, como o $x$ como variável, e verificar se são unidades de sentido de uma função.

$\mathrm{O}$ item (b) teve o objetivo de constatar se os alunos conseguem identificar as unidades simbólicas significativas que são comuns entre as duas expressões obtidas nas atividades anteriores, em especial a variável como expoente nas expressões.

O objetivo do item (c) foi estabelecer relações entre as representações algébricas obtidas pelos alunos com as funções já estudadas e verificar se eles interpretavam as expressões obtidas nas atividades anteriores como representações de um novo tipo de função ainda não estudada por eles. Também queríamos verificar se os alunos conseguiam identificar algumas unidades simbólicas comuns a outras funções já estudadas por eles.

Com os itens (d) e (e), o objetivo era trabalhar a influência das bases das potências presentes nas expressões. Para isso, no item (d), pedimos para os alunos identificarem os valores das 
potências, com o intuito de que suas atenções se voltassem para essa unidade simbólica significativa da representação algébrica e, no item (e), que eles refletissem sobre os valores dessas bases e a relação com o comportamento das funções que modelam as situações.

A Figura 6 apresenta a quarta atividade.

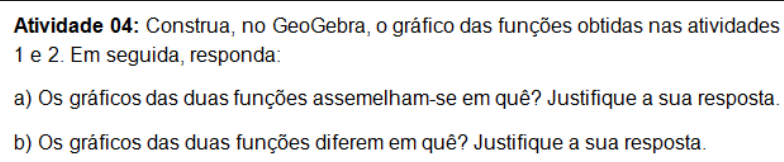

Figura 6: 4. ${ }^{\mathrm{a}}$ atividade extraída do instrumento de intervenção.

Tratou-se de uma atividade que explora a conversão do registro algébrico para o registro gráfico das funções obtidas anteriormente. Para isso, solicitamos que se utilizasse o software GeoGebra. Optamos pela representação do gráfico no software, pois as funções ainda são desconhecidas para os alunos e queríamos evitar o que Duval chama de utilização das abordagens ponto a ponto e extensão do traçado (muito frequentes no ambiente papel e lápis) na construção de gráficos, abordagens que recorrem a valores pontuais do domínio para encontrar o correspondente na imagem, uma vez que podem comprometer a aprendizagem da função estudada.

No item (a), os alunos deveriam identificar as variáveis visuais pertinentes dos gráficos, como o crescimento e o decrescimento acelerado, ou seja, as implicações das unidades simbólicas significativas da representação algébrica das atividades 1 e 2 nas variáveis visuais pertinentes da representação gráfica. No item (b), os alunos deveriam sinalizar o fato de um gráfico ser crescente e o outro decrescente.

Na Figura 7 é apresentada a atividade 5.

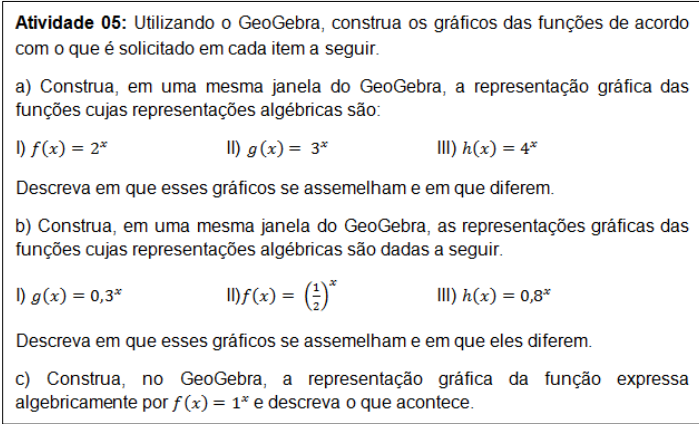

Figura 7: 5. ${ }^{\mathrm{a}}$ atividade extraída do instrumento de intervenção.

Nessa atividade, o objetivo foi possibilitar ao aluno a associação entre as unidades simbólicas significativas do registro algébrico e as variáveis visuais pertinentes do registro gráfico desse tipo de função. Os três itens presentes na atividade foram elaborados como o objetivo propósito de contribuir com o estudo da definição da função exponencial e das características algébrica e gráfica dessa função.

O item (a) foi elaborado com o objetivo de verificar se os alunos percebiam que as três funções são crescentes, que cada função cresce de maneira diferente e se eles associariam a esses dois acontecimentos a base das potências presentes nos registros algébricos das funções. Para responder, os alunos poderiam indicar que as três funções são crescentes e justificar isso pelo fato de as bases das três potências serem maiores do que 1. Eles também poderiam sinalizar que as funções crescem de maneira diferente e justificar indicando que as bases das potências presentes nos registros algébricos das funções possuem valores diferentes.

No item (b), queríamos verificar se os alunos compreendem que as três funções são decrescentes, se eles identificam que o decrescimento das três funções ocorre de maneiras 
diferentes e se eles associam a esses dois acontecimentos a base das potências. Para a resolução, os alunos poderiam indicar que, em função da base das potências ser menor do que 1, as funções são decrescentes e, se as bases possuírem valores diferentes, os decrescimentos são diferentes.

No item (c), nosso objetivo era levar os alunos a perceber a impossibilidade de a base das potências da representação algébrica desse tipo de função ser igual a 1 . Como resposta a esse item, os alunos poderiam indicar que, caso a base seja 1, a função será constante.

A Figura 8, a seguir, apresenta a sexta atividade que compõe o instrumento de intervenção.

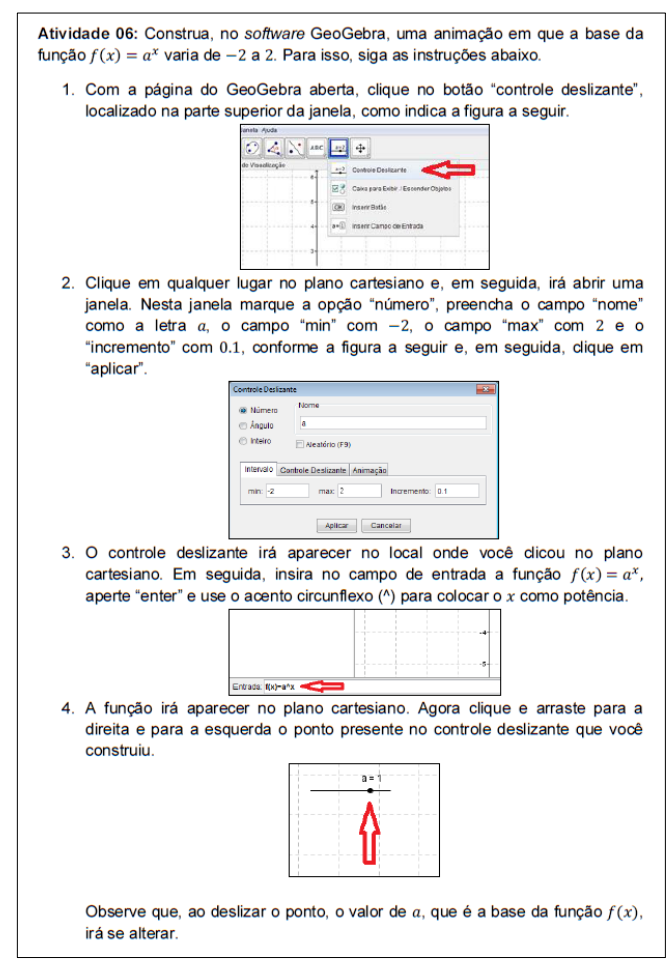

Figura 8: Primeira parte da $6{ }^{\mathrm{a}}$ atividade extraída do instrumento de intervenção.

Na sexta atividade, exploramos a condição do $a$ (base da potência que compõe o registro algébrico da função exponencial) para que a função exista. Para isso, solicitamos que os alunos construíssem no GeoGebra o gráfico da função $f(x)=a^{x}$ e que eles criassem um controle deslizante para a base $a$. Para a realização da atividade, os alunos foram orientados sobre os passos que deveriam seguir, como é possível observar na Figura 8.

Com essa abordagem, nosso objetivo era explorar uma unidade simbólica significativa do registro algébrico da função exponencial, a base da potência $(a)$ e, com o auxílio do software GeoGebra, proporcionar aos alunos a associação dela com as variáveis visuais pertinentes correspondentes na representação gráfica.

Essa atividade continua com cinco indagações e, para responder a essas perguntas, os alunos poderiam recorrer à construção realizada anteriormente. As perguntas são: 


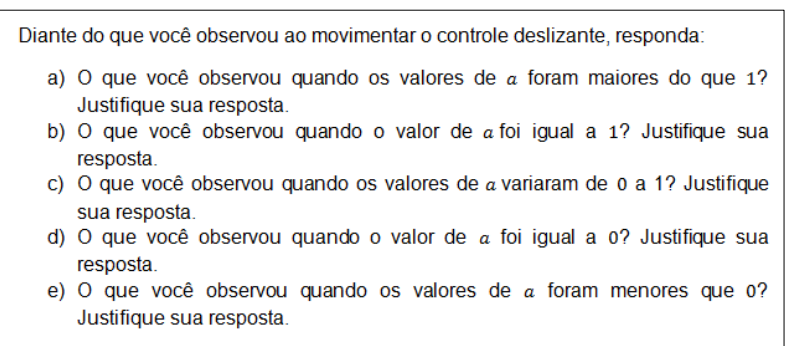

Figura 9: Continuação da 6. ${ }^{a}$ atividade extraída do instrumento de intervenção.

Com os cinco itens, queríamos investigar se os alunos reconheciam o "a" como uma unidade de sentido e se eles compreendiam a implicação do seu valor quando se converte o registro de algébrico para o registro gráfico.

Com o item (a), o objetivo era observar se os alunos percebiam que, quando o valor da base da potência for maior que 1, a função será crescente. No item (b), queríamos verificar se os alunos percebiam que, quando a base da potência for igual a 1, a função será constante. No item (c), nosso propósito era constatar se os alunos eram capazes de notar que, quando os valores da base da potência ficam entre 0 e 1, a função é decrescente.

No item (d), o objetivo era analisar se os alunos percebiam a impossibilidade de a base da potência ser igual a 0 . No item (e), queríamos examinar se os alunos atentavam que, quando os valores da base da potência são menores que 0 , a função não é definida.

Para responder esses itens, os alunos deveriam observar o registro algébrico e gráfico da função, simultaneamente, e isso é possível, pois o software GeoGebra possui a janela de álgebra e a janela gráfica na mesma interface. Foi esperado que eles notassem que o registro gráfico da função exponencial possui um determinado comportamento, quando a base da potência assume valores específicos.

Na Figura 10, é apresentada a última atividade do instrumento de intervenção.

Atividade 07: Diante do que foi observado nas seis atividades anteriores, quais as

principais características desse tipo de função?

Figura 10: 7. ${ }^{\mathrm{a}}$ atividade extraída do instrumento de intervenção.

Essa atividade foi planejada para reunir os conceitos trabalhados nas seis atividades anteriores de modo que eles deveriam escrever as características da função estudada. Acreditávamos que os alunos poderiam, depois de responderem as questões anteriores, chegar a características que se aproximassem de maneira não formal da definição da função exponencial, por exemplo, indicar que a base da função exponencial tem que ser maior que 0 e diferente de 1 , que o domínio é real, a imagem positiva e indicar a lei de formação dessa função.

Nessa atividade, os alunos deveriam recorrer às atividades anteriores. Eles deveriam se lembrar das propriedades exploradas e articular os registros de representação algébrico e gráfico da função estudada, associar as unidades simbólicas significativas às variáveis visuais pertinentes desse tipo de função e escrever, em língua materna, as características que eles observaram.

\section{Análise da intervenção}

Para responder a questão de pesquisa e atingir o objetivo proposto, foi realizada uma análise qualitativa das respostas dadas pelos alunos nas atividades que compõem o instrumento, as quais Ludke e André (1996) consideram ser uma pesquisa em que os dados obtidos são descritivos, alcançados no contato direto entre o pesquisador e o fenômeno estudado e que prioriza mais o processo do que o produto da investigação. Sendo assim, esta pesquisa foi realizada com um grupo de alunos, em que procuramos compreender como a utilização do software GeoGebra na 
mobilização, na manipulação e na coordenação de representações semióticas durante uma atividade interventiva pode auxiliar os alunos do Ensino Médio na aprendizagem de função exponencial.

O instrumento foi aplicado a 12 alunos do $1 .^{\circ}$ ano do Ensino Médio de um colégio estadual, localizado no extremo sul da Bahia, que demonstraram interesse em participar como voluntários da aplicação, a qual foi realizada no turno oposto ao que eles estudavam. Esses alunos, ainda, não haviam aprendido o conteúdo de função exponencial, e sim as funções polinomiais do $1 .^{\circ}$ e $2 .^{\circ}$ graus e função modular. Ressaltamos que, por termos optado por uma análise qualitativa, apesar de 12 alunos terem participado da pesquisa, foram analisadas apenas as resposta de três deles. Salientamos, ainda, que a visão geral da turma foi construída com base nas respostas de três alunos, os quais apresentaram desempenhos distintos no bimestre que antecedeu a intervenção.

O instrumento foi trabalhado nessa turma por um período de quatro aulas de 50 minutos cada, divididos em dois encontros. Para responder três das sete atividades do instrumento, foi solicitado que os alunos utilizassem o software GeoGebra. No tocante às dificuldades no manuseio do software, estas eram solucionadas com instruções diretas dadas por nós.

A dinâmica de aplicação do instrumento ocorreu da seguinte forma: no início do encontro foi entregue aos alunos o instrumento para que eles realizassem as atividades e utilizassem o software GeoGebra, quando solicitado na atividade. Ao terminar de responder, os instrumentos foram recolhidos e o conteúdo formalizado. Quando surgia alguma dúvida referente à resolução das atividades, os alunos eram levados a refletir sobre as indagações realizadas.

Com a finalidade de fazer um recorte dos dados produzidos, realizamos a análise das respostas de três sujeitos. O critério para selecioná-los como interlocutores foram as notas obtidas no bimestre que antecedeu a intervenção, queríamos analisar a respostas de alunos com diferentes níveis de desempenho em matemática, e esse foi o critério utilizado. O primeiro foi um aluno que obteve nota maior ou igual a 8,0, o segundo com nota compreendida no intervalo de 5,0 a 6,0 e o terceiro, o que obteve nota menor ou igual a 3,0.

Adotamos, durante a análise, nomes fictícios para os três interlocutores. Chamamos de André o aluno que obteve, no bimestre que antecedeu a intervenção, nota maior que 8,0; de Bruno o aluno que obteve nota compreendida no intervalo de 5,0 a 6,0; e de Carlos o aluno que obteve nota menor ou igual a 3,0 .

De maneira geral, é possível afirmar que os alunos André e Bruno conseguiram realizar, de maneira satisfatória, as atividades, efetuando as conversões e tratamentos, quando solicitados, bem como as associações entre as unidades simbólicas significativas do registro algébrico às variáveis visuais pertinentes do registro gráfico. Entretanto, o aluno Carlos teve dificuldades na execução das atividades que não exigiam o uso do GeoGebra, deixando alguns itens sem respostas; naquelas que solicitavam o uso do software, ele obteve um melhor desempenho, revelando a contribuição dessa tecnologia na aprendizagem de função exponencial.

\section{Atividade 1}

Quanto à primeira atividade, André efetuou as conversões necessárias para transformar as informações matematicamente pertinentes do registro expresso em língua materna, como o valor inicial do terreno e a taxa de valorização, em registro numérico, bem como realizar os tratamentos necessários no preenchimento completo do quadro. Esse aluno ainda conseguiu generalizar a situação do problema apresentada, o que demonstra que ele foi capaz de mobilizar as informações necessárias para se chegar à resposta, conforme podemos observar na Figura 11. 


\begin{tabular}{|c|c|c|}
\hline Tempo & Expressāo & $\begin{array}{l}\text { Valor do terreno em } \\
\text { Reais }\end{array}$ \\
\hline Hoje & 14000 & 14000 \\
\hline Após 1 ano & $\begin{array}{l}14000+14000 \times 0,08 \\
=14000 \times(1+0,08) \\
=1400 \times 10.08\end{array}$ & 15120 \\
\hline Após 2 anos & $\begin{aligned} 14000 \times 1,08 & +14000 \times 1,08 \times 0,08 \\
& =1400 \times 1,08(1+0,08) \\
& =14000 \times 1,08^{2}\end{aligned}$ & 16329,60 \\
\hline Após 3 anos & 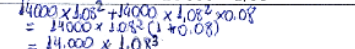 & $29.650,97$ \\
\hline Após 4 anos & 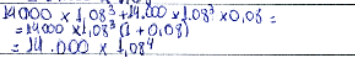 & $19.016,85$ \\
\hline \multicolumn{3}{|c|}{$\begin{array}{l}\text { Escreva uma expressäo capaz de determinar o valor do imóvel com o passar da } \\
\text { tempo. }\end{array}$} \\
\hline \multicolumn{3}{|c|}{$14.000 \times 1.08^{x}$} \\
\hline
\end{tabular}

Figura 11: Resposta do aluno André.

Por seu turno, o aluno Bruno fez a transformação do registro expresso em língua materna para o registro numérico, preenchendo o quadro, entretanto ele se equivocou em alguns tratamentos nesse processo, como não colocar os termos comuns na expressão em evidência, mas apresentou o valor correto do terreno no período de tempo solicitado. Quanto à generalização da situaçãoproblema, assim como o aluno André, Bruno a realizou corretamente, demonstrando ter conseguido, também, mobilizar as informações necessárias para chegar à resposta da expressão algébrica.

O aluno Carlos conseguiu identificar as informações matematicamente pertinentes da situaçãoproblema, uma vez que ele começou a preencher o quadro, contudo ele não foi capaz de executar os tratamentos necessários no registro numérico. Mesmo diante dessa situação, ele determinou o valor do terreno nos períodos de tempo solicitado. Esse aluno não foi capaz de generalizar a situação-problema proposta, como é possível observar na Figura 12.

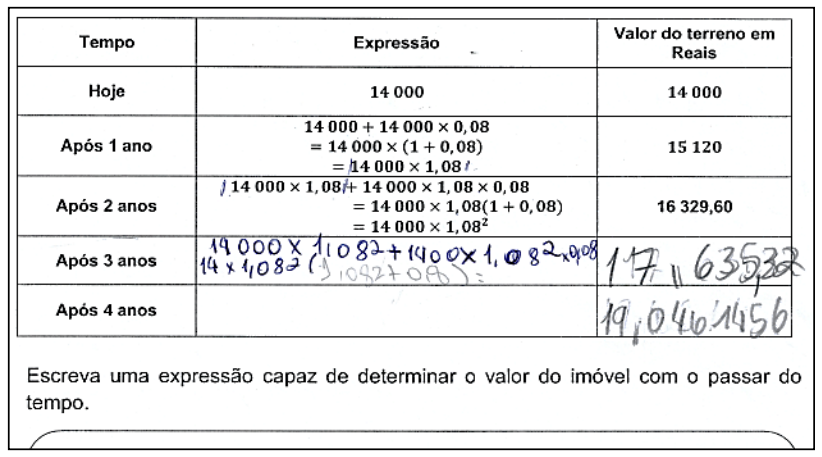

Figura 12: Resposta do aluno Carlos.

Como é possível observar, ele realizou os tratamentos no registro numérico de forma que o fato de não colocar os fatores comuns em evidência não o impediu de encontrar o valor do terreno, porém ele não conseguiu realizar a conversão do registro numérico para o algébrico. Dessa forma, não é possível analisar a resposta dada por esse aluno e emitir um posicionamento sobre o seu aprendizado em Matemática, pois, de acordo com Duval (2011b), se quisermos entender como um indivíduo faz Matemática, as conversões devem ser analisadas, e é exatamente o que o aluno não efetuou.

\section{Atividade 2}

Por se tratar de uma atividade semelhante à atividade 1 , diferindo apenas pelo fato de a situação-problema poder ser modelada por uma função exponencial decrescente, o desempenho dos alunos foi o mesmo da atividade 1.

O aluno André, mais uma vez, conseguiu identificar as informações matematicamente pertinentes que estavam expressas em língua materna no enunciado da atividade, que eram o valor 
inicial do automóvel e a taxa de desvalorização, realizar a conversão para registro numérico, bem como os tratamentos necessários para realizar o preenchimento do quadro. Nessa atividade, ele também foi capaz de generalizar a situação-problema.

O aluno Bruno, nessa atividade, teve o mesmo desempenho da atividade anterior. Ele identificou as informações matematicamente pertinentes presentes no enunciado da situaçãoproblema, realizou a conversão para o registro numérico, bem como os tratamentos solicitados pela atividade. Ele também conseguiu generalizar a situação-problema, como é possível observar na Figura 13.

\begin{tabular}{|c|c|c|}
\hline Tempo de uso & Expressão & $\begin{array}{l}\text { Valor do veiculo em } \\
\text { Reais }\end{array}$ \\
\hline Hoje & 36,000 & 36,000 \\
\hline 1 ano & $36,000-316000 \times 0,00$ & 33840 \\
\hline 2 anos & 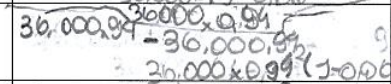 & $=\quad 31809,60$ \\
\hline 3 anos & $\begin{array}{c}36,000,94-36,000,9 \\
36,000 \times 99^{3}=2\end{array}$ & $29,900,5$ \\
\hline 4 anos & $36,000 \times 94+36,000 \times 99^{6}$ & $28,106,00$ \\
\hline $\begin{array}{l}\text { Determine uma } \\
\text { do tempo. }\end{array}$ & $\begin{array}{l}36.000 \cdot 0,9 y^{*} \\
\text { xpressão que modele a desvalorizaçăo do au }\end{array}$ & utomóvel com o pa: \\
\hline
\end{tabular}

Figura 13: Resposta do aluno Bruno.

Carlos, assim como os colegas, repetiu o mesmo desempenho da atividade anterior. Ele identificou as informações matematicamente pertinentes da situação-problema, uma vez que conseguiu calcular os valores do veículo nos períodos de tempo solicitado. Entretanto, ele não conseguiu realizar as transformações necessárias para preencher o campo das expressões no quadro. Nessa atividade, ele também não pôde generalizar a situação-problema, uma vez que não foi capaz de realizar a mobilização necessária para chegar à generalização, como é possível observar na Figura 14.

\begin{tabular}{|c|c|c|}
\hline Tempo de uso & Expressão & $\begin{array}{c}\text { Valor do veiculo em } \\
\text { Reais }\end{array}$ \\
\hline Hoje & & \\
\hline 1 ano & & 33840 \\
\hline 2 anos & & $-31809,60$ \\
\hline 3 anos & $29,901.024$ \\
\hline 4 anos & $28,106,96256$ \\
\hline $\begin{array}{l}\text { Determine uma expressão que modele a desvalorizaçăo do automóvel com o passar } \\
\text { do tempo. }\end{array}$ \\
\hline
\end{tabular}

Figura 14: Resposta do aluno Carlos

Assim, é possível perceber, mais uma vez, que nas tarefas que demandam maior custo cognitivo, que, no caso, são aquelas que exigem uma conversão, Carlos apresentou dificuldades de realizá-las, deixando em branco as tarefas que exigiam esse tipo de transformação, o que pode ser indício da falta de habilidade desse aluno em efetuar as conversões em Matemática. 


\section{Atividade 3}

Para realizar essa atividade, era necessário recorrer às expressões obtidas nas atividades 1 e 2 . Os cinco itens que compõem a atividade 3 foram respondidos pelos alunos André e Bruno. $\mathrm{O}$ aluno Carlos, no entanto, respondeu apenas o item (a), uma vez que ele não obteve as expressões das atividades anteriores.

Quanto ao item (a), os alunos André e Bruno responderam de maneira correta, demonstrando que identificaram, nos registros algébricos das expressões obtidas, unidades simbólicas significativas próprias das funções. Podemos observar, no Quadro 1, a resposta de André e, no quadro 2, a de Bruno.

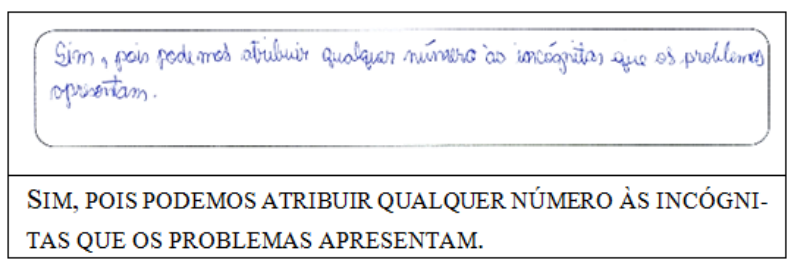

Quadro 1: Resposta do aluno André

\begin{tabular}{|c|}
\hline 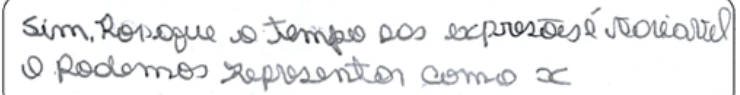 \\
\hline $\begin{array}{l}\text { SIM, PORQUE O TEMPO DAS EXPRESSÕES É VARIÁVEL E PODE- } \\
\text { MOS REPRESENTAR COMO X. }\end{array}$ \\
\hline
\end{tabular}

Quadro 2: Resposta do aluno Bruno

A resposta do aluno André chama a atenção para a unidade simbólica significativa $x$ que é a variável das expressões, indicando que ela pode receber qualquer valor.

No item (b), André e Bruno demonstraram identificar semelhanças entre as unidades simbólicas significativas das duas expressões, conforme podemos observar na respostas do aluno Bruno, na qual ele indica a multiplicação e a variável $x$ como semelhantes, nas duas expressões, que pode ser observado no Quadro 3.

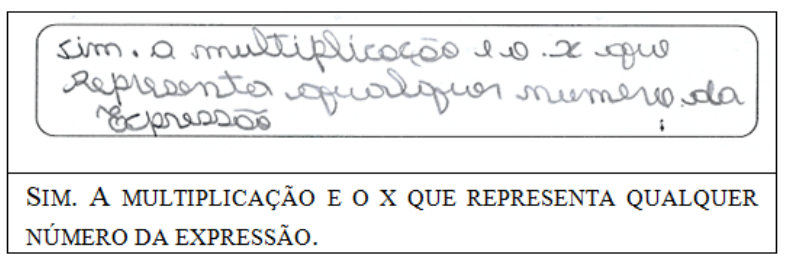

Quadro 3: Resposta do aluno Bruno

Observando as respostas dadas pelos alunos, além de percebermos que eles compreenderam a proposta da atividade, focaram suas atenções para $x$ e afirmaram, de maneira correta, que $x$ assume o papel de variável na expressão, compreendemos que esses alunos construíram a noção de variável.

No item (c), era necessário que os alunos associassem as unidades simbólicas significativas do registro algébrico das expressões obtidas nas atividades 1 e 2 com as unidades simbólicas significativas do registro algébrico de outras funções já estudadas por eles e indicassem em que são diferentes. Os alunos André e Bruno conseguiram realizar essa comparação, apesar de a resposta de Bruno ainda ser pouco consistente e sem justificativa, como podemos observar nos Quadros 4 (resposta do aluno André) e 5 (resposta do aluno Bruno). 


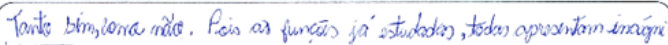

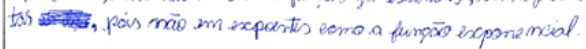

TANTO SIM, COMO NÃO. POIS AS FUNÇÕES JÁ ESTUDADAS,

TODAS APRESENTAM INCÓGNITAS, POIS NÃO EM EXPOENTES

COMO A FUNÇÃO EXPONENCIAL.

Quadro 4: Resposta do aluno André

Sim. A Funcers as segunder grau

SIM. A FUNÇÃO DO SEGUNDO GRAU.

Quadro 5: Resposta do aluno Bruno

No item (d) ambos os alunos (André e Bruno) indicaram as bases das potências que aparecem nas expressões da primeira e da segunda atividade. Como podemos observar na resposta dos alunos André e Bruno, Quadro 6 e 7, respectivamente.

\begin{tabular}{|l|}
\hline $\begin{array}{l}\text { Prumiva atividade: } 1.08 \\
\text { Segunda atuidade: } 0.94\end{array}$ \\
\hline PRIMEIRA ATIVIDADE: 1,08 \\
SEGUNDA ATIVIDADE: 0,94 \\
\hline
\end{tabular}

Quadro 6: Resposta do aluno André.

\begin{tabular}{|l|}
\hline $1,08 / 0,94$ \\
\hline $1,08 / 0,94$ \\
\hline
\end{tabular}

Quadro 7: Resposta do aluno Bruno.

No item (e), tanto o aluno André quanto o aluno Bruno indicaram as bases das potências que compõem o registro algébrico das funções encontradas nas atividades 1 e 2 como uma unidade matematicamente pertinente, uma vez que elas indicam o que acontece no comportamento da função quando essas bases assumem diferentes valores. Com isso, é possível afirmar que eles se aproximaram de uma parte do conceito da função estudada. No Quadro 8, é possível perceber, na resposta do aluno André, essa identificação.

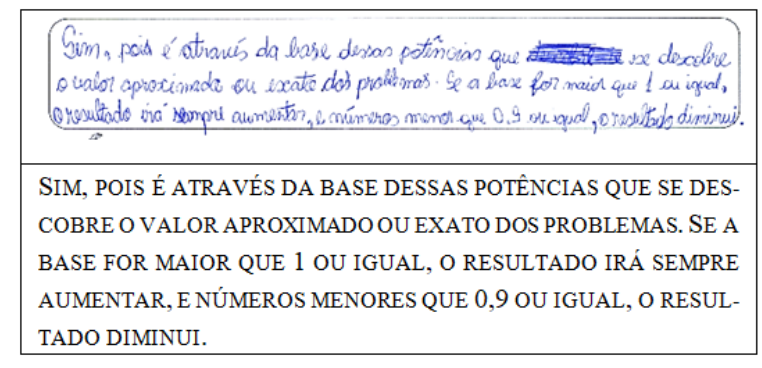

Quadro 8: Resposta do aluno André.

$\mathrm{Na}$ resposta dada pelo aluno André, é possível perceber que ele conseguiu reconhecer a base das potências que compõem as expressões como uma unidade simbólica significativa, uma vez que ela indica os valores em que a função exponencial terá valores diferentes. 


\section{Atividade 4}

Assim como na atividade 3, na atividade 4 necessitava-se das expressões obtidas nas atividades 1 e 2, portanto, mais uma vez, o aluno Carlos não respondeu os dois itens que compõem a atividade, uma vez que ele não obteve essas expressões. Era necessário, também, a coordenação entre os registros de partida, que foram as expressões obtidas nas atividades 1 e 2 , e os de chegada, que foram os registros gráficos construídos com o auxílio do GeoGebra.

Quanto ao item (a), o aluno André conseguiu identificar uma variável visual pertinente do registro gráfico, que é a característica da curva da função exponencial. Isso indica que esse item levou o aluno a observar a propriedade relativa ao registro gráfico da função estudada e que ele foi capaz de realizar a coordenação entre os registros algébrico e gráfico, como podemos verificar no Quadro 9.

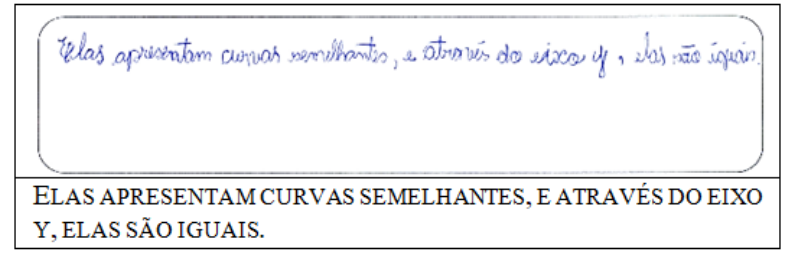

Quadro 9: Resposta do aluno André.

Por sua vez, o aluno Bruno teve dificuldades de identificar a variável visual pertinente referente à característica da curva exponencial. Ele acabou confundindo o registro gráfico da função exponencial com o da função polinomial do $2 .^{\circ}$ grau, indicando que a concavidade do registro gráfico das funções está voltada para cima. Isso mostra que o conhecimento sobre o registro gráfico da função exponencial ainda é insipiente, que é aceitável, uma vez que os estudos dessa função se iniciaram com o presente instrumento, como é possível observar no Quadro 10.

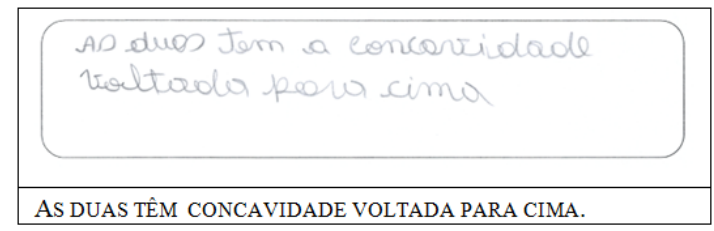

Quadro 10: Resposta do aluno Bruno.

No que se refere ao item (b), André demonstrou mais habilidade do que Bruno, ao comparar o registro gráfico das duas funções, apesar de ter cometido alguns equívocos. André sinalizou uma informação implícita no registro gráfico das funções, que diz respeito ao ponto de encontro com o eixo $x$ ser diferente, entretanto a representação gráfica da função exponencial não toca esse eixo, apesar de dar essa impressão a quem visualiza o registro gráfico no GeoGebra (a menos que se dê um zoom ao registro). Isso demonstra que André foi capaz de sinalizar uma propriedade importante da função exponencial, o fato de a representação gráfica não interceptar o eixo das abscissas. É possível dizer ainda que, de maneira implícita, esse aluno percebeu que não existe um número real que, elevando a outro número real, resulte em zero, fato que é estudado apenas no registro numérico ou algébrico, como é observado no Quadro 11. 


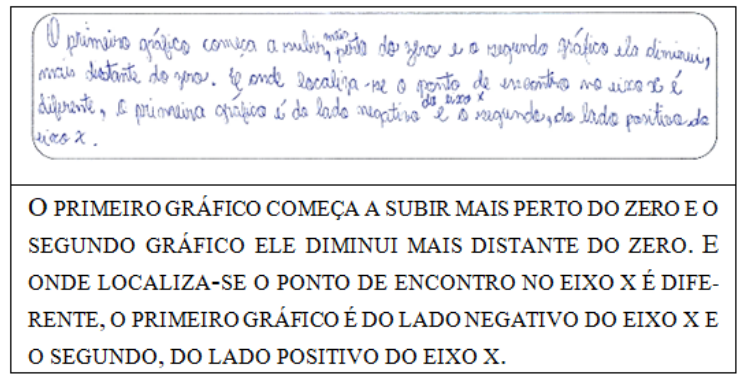

Quadro 11: Resposta do aluno André.

Bruno, por sua vez, indica que uma é positiva e a outra é negativa. Nessa resposta, não é possível constatar se esse aluno tentou informar que uma função está do lado positivo do eixo $x$ e a outra do lado negativo desse mesmo eixo, ou se uma função é crescente e a outra decrescente. $\mathrm{O}$ que se pode afirmar é que ele observou unidades simbólicas significativas que tornam os registros gráficos diferentes (Quadro 12).

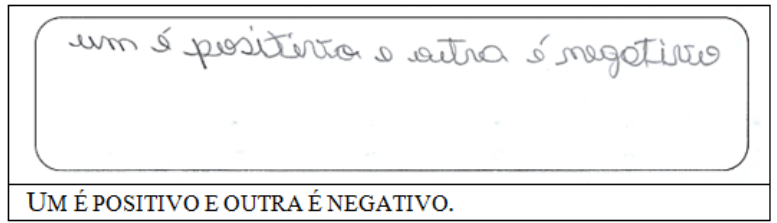

Quadro 12: Resposta do aluno Bruno.

\section{Atividade 5}

Os três itens que compõem essa atividade foram respondidos pelos três alunos. No item (a), o aluno André deu uma resposta bastante detalhada, se comparada com as dos colegas, conseguindo elucidar algumas variáveis visuais pertinentes do registro gráfico da função exponencial. Isso demonstra que os conhecimentos desse aluno acerca do registro gráfico da função exponencial foram construídos de maneira satisfatória, uma vez que ele está fazendo uma interpretação global das propriedades figurais, e que esse item levou o aluno a observar a propriedade relativa ao registro gráfico da função estudada, conforme se observa no Quadro 13.

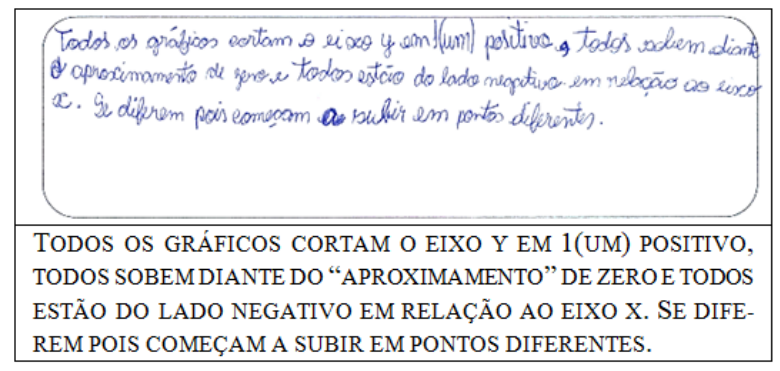

Quadro 13: Resposta do aluno André.

O aluno Bruno respondeu de maneira semelhante a André. Ele realizou uma interpretação global do registro gráfico, indicou que os registros gráficos das funções interceptam o eixo das ordenadas em 1, uma vez que, quando $x$ assumir o valor 0 , a imagem será 1 , independentemente do valor da base da potência que compõe o registro algébrico da função e que as funções crescem de formas diferentes. Isso demonstra que ele também reconheceu algumas variáveis visuais pertinentes do registro gráfico, como é possível observar no Quadro 14. 


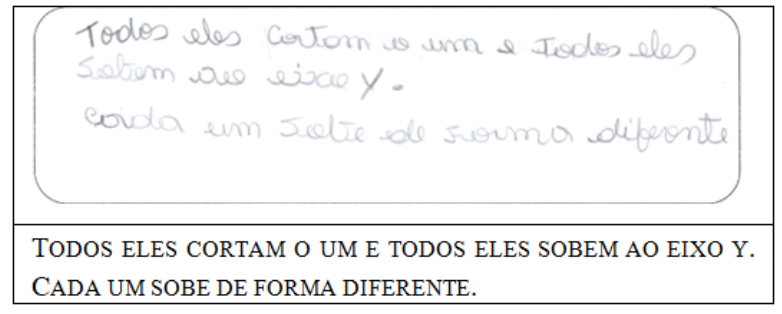

Quadro 14: Resposta do aluno Bruno.

Nesse item, o aluno Carlos sinalizou que os registros gráficos das funções se assemelham nas curvas, indicando essa unidade simbólica significativa da função exponencial. Ele assinalou, também, que os registros gráficos se diferem nas distâncias, na intenção de apontar o crescimento distinto das funções. Entretanto, ele se equivocou quando assinalou que a concavidade dos registros gráficos da função está voltada para cima, confundindo, assim, a curva exponencial com uma parábola. Podemos dizer que esse aluno, apesar das dificuldades apresentadas na primeira parte da intervenção, na qual ele não conseguiu responder uma parte das atividades 1 e 2 nem as atividades03 e 4, que não solicitavam o uso do software GeoGebra. Nessa atividade, com o uso do software, ele apresentou um avanço considerável, conseguindo apontar unidades simbólicas significativas.

Isso só foi possível porque o aluno realizou a conversão do registro algébrico para o registro gráfico com o auxílio do software, uma vez que ele permite fazer uma análise global das propriedades figurais e relacioná-las com as unidades simbólicas significativas da representação algébrica. Possivelmente, no ambiente lápis e papel é difícil, para esse aluno, perceber essa propriedade e estabelecer tais relações, visto que, sem conhecer as unidades simbólicas significativas da função exponencial, ele recorreria à construção ponto a ponto ou por extensão de traçado. É possível observar a resposta de Carlos no Quadro 15.

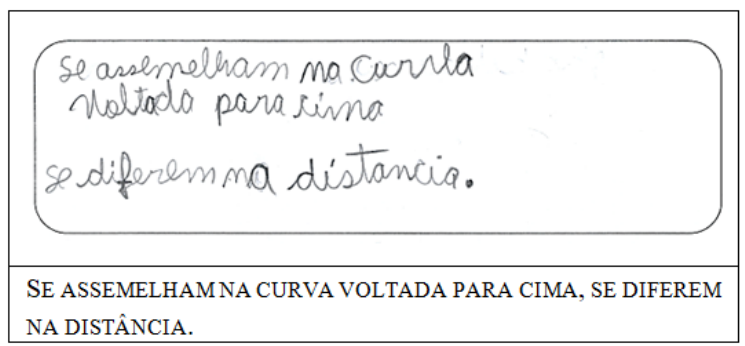

Quadro 15: Resposta do aluno Carlos.

No item (b), as respostas dos três sujeitos foram semelhantes à do item anterior, pois o que muda nesse item é o fato de as funções serem decrescentes. O aluno André, mais uma vez, conseguiu evidenciar algumas variáveis visuais pertinentes, como o fato de o registro gráfico da função exponencial cortar o eixo das ordenadas em 1 e a função ser crescente. Ele também chama a atenção para a diferença na forma como as funções crescem, destacando uma propriedade importante do registro gráfico da função exponencial, que é o comportamento da função de acordo com a base da potência que compõe o registro algébrico da função exponencial. Isso revela que esse aluno foi capaz de associar a unidade simbólica significativa referente à base da potência do registro algébrico da função à unidade simbólica significativa referente à forma como a função cresce, o que é possível observar no Quadro 16. 


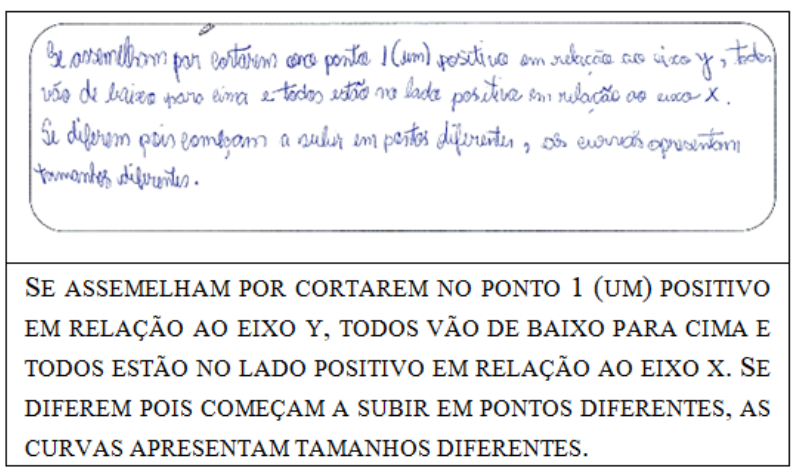

Quadro 16: Resposta do aluno André.

O aluno Bruno indicou que os registros gráficos das funções interceptam o eixo das ordenadas em 1 e as funções sobem. Com o auxílio do software, Carlos, mais uma vez, conseguiu realizar a atividade, respondendo de maneira semelhante ao item anterior. Ele apontou que os registros gráficos das funções se assemelham nas curvas, apontando uma unidade simbólica significativa referente à característica da curva da função exponencial. Ele também assinalou que os registros se diferem nas distâncias, ou seja, na maneira como decrescem.

No item (c), os três sujeitos indicaram que o registro gráfico da função, cuja representação algébrica é $f(x)=1^{x}$, é uma reta. O aluno André deu uma resposta mais completa, descrevendo como o registro gráfico da função se apresenta. Isso indica que ele identificou as variáveis visuais pertinentes do registro gráfico. Resposta de André (Quadro 17).

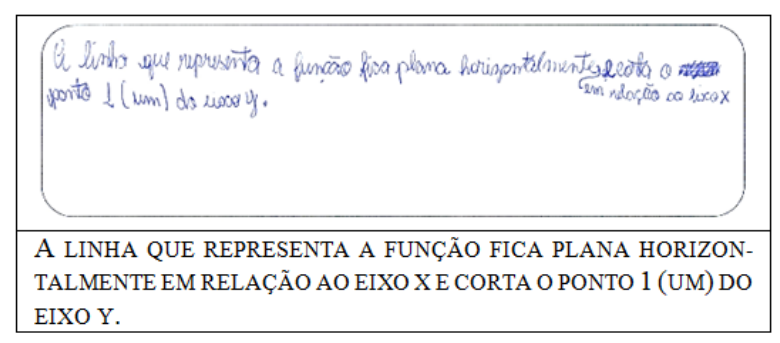

Quadro 17: Resposta do aluno André.

O aluno Carlos deu uma resposta simples, revelando que ele observou o que acontece com o registro gráfico da função exponencial, quando a base assume o valor 1. Isso indica que ele conseguiu associar as unidades simbólicas significativas do registro algébrico às variáveis visuais pertinentes do registro gráfico, conforme pode ser observado no Quadro 18.

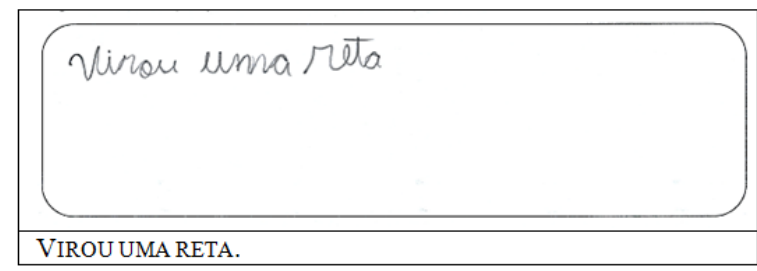

Quadro 18: Resposta do aluno Carlos.

\section{Atividade 06}

Nessa atividade, os três sujeitos descreveram o comportamento do registro gráfico, quando os valores da base da potência no registro gráfico da função assumiam valores distintos. Foi possível observar nas respostas deles, que eles conseguiram manipular de maneira efetiva o registro algébrico, essa por sua vez mediada pelo GeoGebra 
No item (a), os alunos descreveram o que observaram no registro gráfico. O aluno André indicou que o registro gráfico da função ficaria do lado positivo do eixo $x$ e que a curva se inclinaria à medida que o valor da base aumentasse. Isso aponta que André conseguiu coordenar o registro de partida (registro algébrico) e o registro de chegada (registro gráfico). É importante salientar que isso só foi possível porque o GeoGebra permite a manipulação dos dois tipos de registro em uma mesma interface. No Quadro 19, é possível observar a resposta do aluno André.

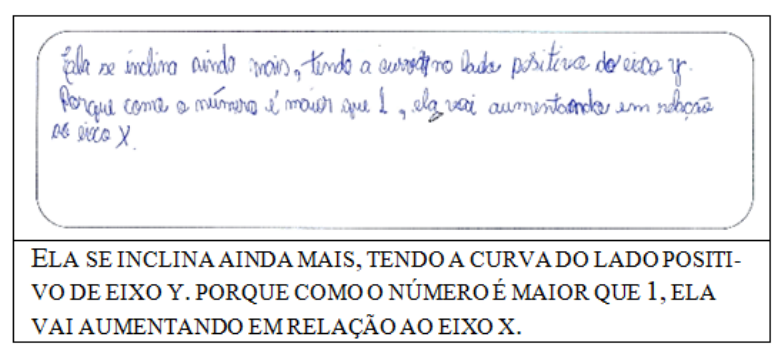

Quadro 19: Resposta do aluno André.

O aluno Bruno indicou que o valor em relação ao eixo $y$ vai aumentando. Já o aluno Carlos assinalou que a reta se torna uma curva e que essa fica do lado positivo do eixo $x$. Ao realizarem essas inferências, Bruno e Carlos demonstraram que conseguiram associar os dois registros e determinar uma característica desse tipo de função. Isso é indício de que, ao mobilizar, coordenar e manipular os registros algébrico e gráfico de uma mesma função, o aluno realiza, segundo Duval (2011b), uma conversão qualitativa, pois associa as unidades simbólicas significativas da representação algébrica às variáveis visuais pertinentes da representação gráfica.

No item (b), o aluno André indicou o que acontecera com o registro gráfico da função exponencial, quando a base da potência que compõe o registro algébrico da função exponencial assume o valor 1 . Na justificativa apresentada, é possível perceber que ele foi capaz de associar a propriedade de potência na qual o número 1 elevado a qualquer número será sempre 1 ao registro gráfico da função $f(x)=1^{x}$. Isso demonstra que os conhecimentos desse aluno acerca do registro gráfico da função exponencial, nesse item, foram construídos de maneira satisfatória, uma vez que houve a coordenação entra o registro algébrico e gráfico da função. Segundo afirma Duval (2011a), a coordenação entre dois registros de representação possibilita a compreensão do conteúdo estudado. Isso é possível observar no Quadro 20.

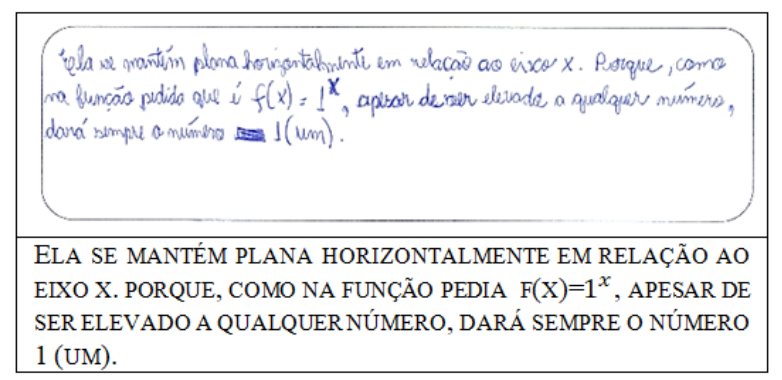

Quadro 20: Resposta do aluno André.

Foi possível identificar, nessa resposta, que André conseguiu coordenar a unidade simbólica significativa referente à base da representação algébrica da função à variável visual pertinente referente à forma do registro gráfico (uma reta paralela ao eixo das abscissas). Os alunos Bruno e Carlos também realizaram essa associação, uma vez que indicaram o comportamento que o registro gráfico tem quando a base da potência no registro algébrico da função exponencial assume valor igual a 1, ou seja, eles conseguiram, por meio da manipulação, coordenar o registro algébrico e gráfico da função, conforme é possível observar na resposta de Carlos (Quadro 21). 


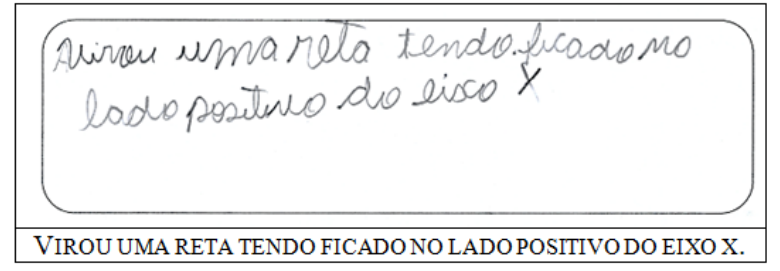

Quadro 21: Resposta do aluno Carlos.

No item (c), os alunos André e Carlos indicaram que o registro gráfico da função se inclina do lado negativo em relação ao eixo das abscissas, uma vez que o decrescimento da função ocorre de maneira mais visível no registro gráfico, no quarto quadrante. O aluno André sinalizou, também, que a função é decrescente, demonstrando que conseguiu, após a manipulação da base da potência que compõe o registro algébrico da função exponencial, coordenar o registro algébrico e gráfico da função.

O aluno Bruno também conseguiu observar o decrescimento, indicando que a função em relação ao eixo das ordenadas vai diminuir, como é possível observar no Quadro 22.

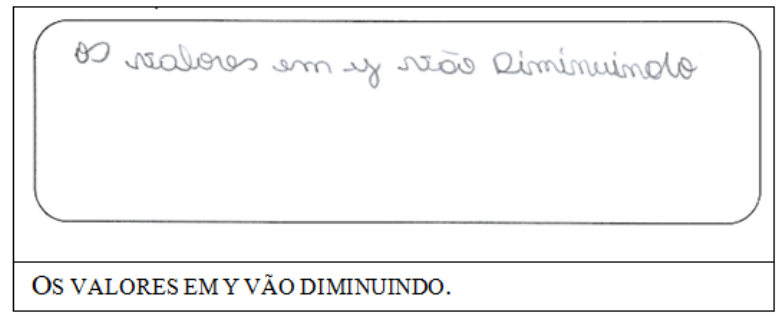

Quadro 22: Resposta do aluno Bruno.

Na resposta dada pelo aluno Bruno, apesar de não haver justificativas, é possível perceber que ele foi capaz de associar a variável visual pertinente correspondente à base da potência que compõe o registro algébrico da função com as unidades simbólicas significativas correspondentes à curva obtida no registro gráfico, uma vez que ele mostrou compreender que, quando a base da função assume valores de 0 a 1 , o registro gráfico da função assume um comportamento decrescente. Isso foi possível porque Bruno realizou uma interpretação global das propriedades figurais, o que possibilitou a coordenação entre os dois registros explorados nesse item (registro algébrico e gráfico) e, como indica Duval (2011b), essa interpretação permite uma análise de congruência entre dois registros de apresentação do objeto estudado.

No item (d), André e Bruno assinalaram que a função não vai existir quando a base da potência da função exponencial assumir valor igual a zero, demonstrando ter coordenado o registro de partida (registro algébrico) com o registro de chegada (registro gráfico), que foi possível por meio da manipulação proporcionada pelo registro algébrico da função (Quadro 23).

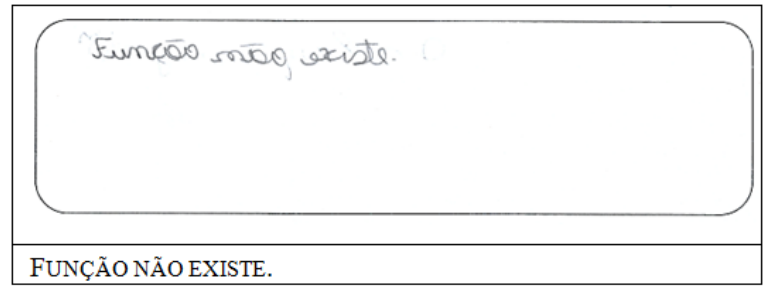

Quadro 23: Resposta do aluno Bruno.

O aluno Carlos descreveu o que observou, indicando que não haverá curva e que a reta ficará no lado positivo do eixo das abscissas. Pode-se notar, nessa resposta, que ele foi capaz de associar a unidade simbólica significativa do registro algébrico com a variável visual pertinente do registro gráfico. Isso foi possível porque o GeoGebra proporcionou a manipulação do registro algébrico e 
a sua coordenação com o registro gráfico, dado que a interface desse software apresenta, simultaneamente, os dois registros.

No item (e), os alunos André e Carlos indicaram que não haverá função, demonstrando que, por meio da manipulação da base da potência que compõe o registro algébrico da função exponencial, eles foram capazes de coordenar o registro algébrico e gráfico dessa função. Na justificativa, eles assinalaram a impossibilidade de essa base assumir o valor zero, revelando que a coordenação entre os dois registros fez emergir (mesmo que de forma intuitiva) uma propriedade importante de potência, que são as restrições que se têm quando a base é zero, pois, quando a base é zero e o expoente recebe números maiores que zero, a função se torna constante, e quando a base é zero e o expoente recebe números menores ou iguais a zero, o resultado não é definido. Na resposta do aluno Carlos, é possível observar a restrição da base (Quadro 24).

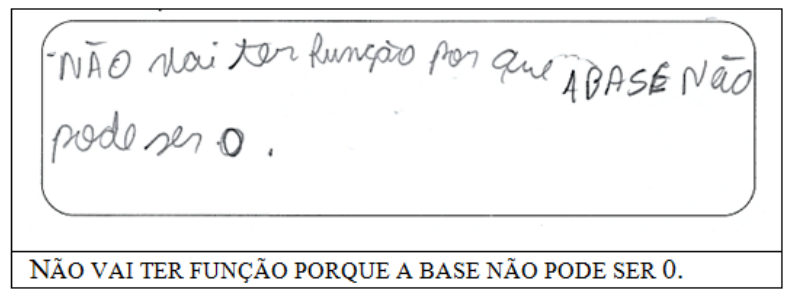

Quadro 24: Resposta do aluno Carlos.

Nesse item, mais uma vez foi observado que houve associação entre os dois registros, mesmo na resposta do aluno Bruno, que apenas indicou a não existência da função exponencial, quando a base da potência que compõe o registro algébrico da função for igual a zero. Isso só ocorreu porque essa atividade possibilitou a coordenação entre os dois registros (Quadro 25).

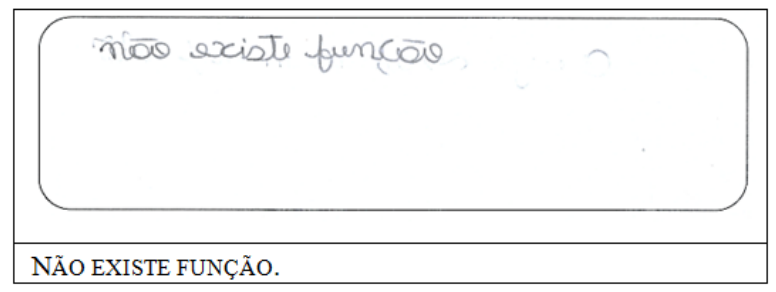

Quadro 25: Resposta do aluno Bruno.

\section{Atividade 7}

Nessa atividade, os três alunos apresentaram respostas perto do que esperávamos, que era elencar elementos que se aproximam da definição da função exponencial, revelando uma interpretação global do que foi trabalhado nas atividades. Isso foi possível porque as seis primeiras atividades que compuseram o instrumento de intervenção propuseram a mobilização de mais de um tipo de registro de representação do objeto do estudo, a manipulação do registro de partida (que, na maioria das vezes, foi o registro algébrico) e a coordenação entre o registro algébrico e gráfico. A coordenação, por sua vez, mediada pelo software GeoGebra, permitiu que os dois registros de representação (algébrico e gráfico) das funções aparecessem simultaneamente na mesma interface. Umas das respostas é a do aluno André (Quadro 26). 


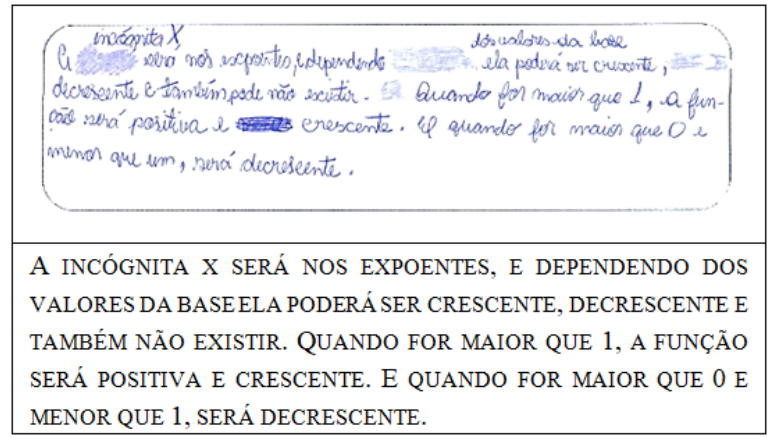

Quadro 26: Resposta do aluno André.

É possível perceber, nessa resposta, que o aluno André destacou elementos importantes da definição, como a lei de formação do registro algébrico da função exponencial, indicando a variável $x$ na posição de um expoente. Ele ressaltou, também, a importância do valor da base da potência que compõe o registro algébrico desse tipo de função, demonstrando ter realizado uma interpretação global das propriedades da função exponencial.

Uma resposta um pouco parecida foi dada pelo aluno Bruno (Quadro 27).

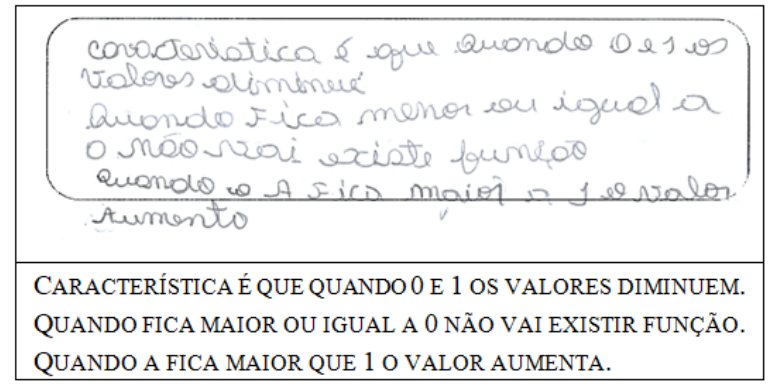

Quadro 27: Resposta do aluno Bruno.

Nessa resposta, é possível perceber que o aluno Bruno ressalta que o comportamento da função exponencial está ligado ao valor da base da potência que compõe o registro algébrico desse tipo de função. Isso demonstra que ele conseguiu associar as unidades simbólicas significativas do registro algébrico às variáveis visuais pertinentes do registro gráfico.

O aluno Carlos também elencou essa unidade simbólica significativa do registro algébrico, como podemos ver no Quadro 28.

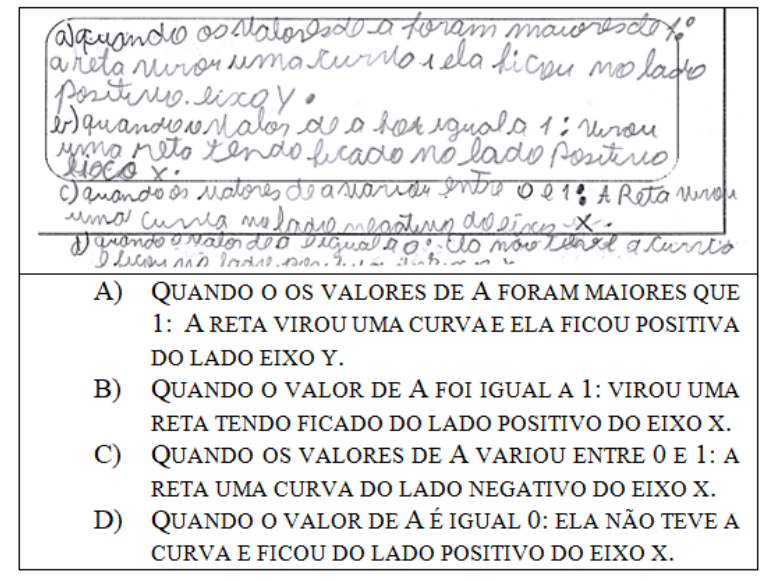

Quadro 28: Resposta do aluno Carlos. 
Ele ressaltou, também, a condição da base da potência que compõe o registro gráfico da função exponencial, reunindo as respostas atribuídas por ele aos itens que compuseram a atividade 6 . É importante destacar que esse aluno não conseguiu responder as quatro primeiras atividades do instrumento de intervenção, pois essas atividades não solicitavam o uso do GeoGebra e esse aluno possuía dificuldades em Matemática. As demais atividades do instrumento foram respondidas e ele foi capaz de chegar a uma resposta significativa nessa última atividade. Desse modo, o software proporcionou a aprendizagem desse aluno e é importante salientar que, se todas as atividades não solicitassem a utilização do software, talvez Carlos não tivesse chegado à resposta dessa última atividade.

Essas três respostas da atividade 7 demonstraram que os alunos conseguiram observar as unidades matematicamente pertinentes no decorrer da resolução das seis questões anteriores. Eles puderam associar os registros explorados nessas atividades, em especial o registro algébrico e gráfico, compreender as características que fazem a função existir ou não, bem como diferentes comportamentos desse tipo de função.

\section{Resultados e reflexões}

A análise das respostas dos interlocutores da investigação permitiu que percebêssemos as contribuições da aplicação da intervenção de ensino apresentada na aprendizagem de função exponencial. Entre as contribuições, é possível destacar os benefícios da utilização do GeoGebra. Esse fato foi confirmado principalmente no instrumento de Carlos, um aluno com baixo rendimento e que não conseguiu responder as atividades em que não utilizou o software. Entretanto, ele foi bem-sucedido nas atividades que solicitavam a utilização do software, inclusive reuniu algumas características da função exponencial na atividade 7.

Em resposta à questão de pesquisa, é possível afirmar que as atividades que compuseram o instrumento de intervenção permitiram que os alunos mobilizassem, manipulassem e coordenassem os diferentes tipos de registro de representação semiótica da função exponencial, como evidenciado nas discussões das atividades. Pode-se destacar, também, que, de maneira geral, os alunos conseguiram realizar a conversão entre os registros e, segundo afirma Duval: “[...] do ponto de vista cognitivo, é a atividade de conversão que aparece como a atividade de transformação representacional fundamental, aquela que conduz ao mecanismo subjacente à compreensão" (2011a, p. 16).

Nesse sentido, por terem realizado na maior parte das atividades a conversão entre os registros de representação exponencial, concluímos que a intervenção contribuiu com a aprendizagem do objeto estudado por parte dos sujeitos envolvidos na pesquisa. Esses resultados revelam as contribuições da TRRS e do software GeoGebra como alternativa para o estudo de função exponencial que pode possibilitar uma maior compreensão desse conteúdo por parte dos alunos.

Por fim, esperamos que a nossa proposta de intervenção possa contribuir para a aprendizagem e servir de inspiração, sendo replicada na íntegra ou de maneira adaptada por nossos colegas que lecionam Matemática, no momento de trabalhar com a função exponencial, uma vez que a proposta de intervenção alia uma teoria cognitivista a uma tecnologia digital, que pode motivar os alunos em seus estudos, levando o aprendiz a observar propriedades, investigar e fazer conjecturas, cabendo ao professor o papel de orientador no desenvolvimento das tarefas, o que configura o binômio ensino-aprendizagem. 


\section{Referências}

BORBA, M. C.; PENTEADO, M. G. Informática e Educação Matemática. Belo Horizonte: Autêntica, 2003.

BORBA, Marcelo de Carvalho; SILVA, Ricardo Scucuglia R. da; GADANIDIS, George. Fases das tecnologias digitais em Educação Matemática: sala de aula internet e movimento. Belo Horizonte: Autêntica, 2014.

BRASIL. Secretaria de Educação Fundamental. Parâmetros Curriculares Nacionais: Matemática. Brasília: MEC/SEF, 1999. Disponível em: http://portal.mec.gov.br/seb/arquivos/pdf/livro03.pdf .

DUVAL, Raymond. Semiósis e pensamento humano: registro semiótico e aprendizagens intelectuais. Tradução de Lênio Fernandes Levy e Marisa Rosâni Abreu da Silveira. São Paulo: Livraria da Física, 2009.

DUVAL, Raymond. Registros de representações semiótica e funcionamento cognitivo da compreensão matemática. In: MACHADO, S. D. A. (Org.). Aprendizagem em matemática: registros de representação semiótica. Campinas: Papirus, 2013.

DUVAL, Raymond. Ver e ensinar matemática de outra forma: entrar no modo matemático de pensar os registros de representação semiótica. In: CAMPOS, T. M. M. (Org.). Tradução de Marlene Alves Dias. São Paulo: Proem, 2011a.

DUVAL, Raymond. Gráficos e equações: a articulação de dois registros. Tradução de Méricles Thadeu Moretti. Revista REVEMAT, Florianópolis, v. 6, n. 2, p. 96-112, 2011b. doi: 10.5007/1981-1322.2011v6n2p96. [GS Search].

FREITAS, Rita Lobo; ALMOULOUD, Saddo Ag. Representações sobre função exponencial. Revista de Produção Discente em Educação Matemática, São Paulo, v. 3, n. 2, p. 135-153, 2014. Disponível em: http://revistas.pucsp.br/index.php/pdemat/article/view/21260/15542. [GS Search].

LUDKE, Menga; ANDRÉ, Marli E. D. A. Pesquisa em educação: abordagens qualitativas. São Paulo: EPU, 1986.

MENDONÇA, Mariana Silva; PIRES, Rogério Fernando. Registro de Representação Semiótica e Tecnologias Digitais na Aprendizagem de Função Exponencial, São Paulo, 2016. Disponível em: http://www.sbembrasil.org.br/enem2016/anais/pdf/7010_3232_ID.pdf. [GS Search].

OLIVEIRA, Rafael Henrique de. Um estudo sobre a função exponencial. Dissertação (mestrado) Universidade Estadual Paulista, Instituto de Geociências e Ciências Exatas, 2015. Disponível em: https://repositorio.unesp.br/bitstream/handle/11449/132123/000853553.pdf?sequence=1. [GS Search].

PIRES, Rogerio Fernando. Função: concepções de professores e estudantes dos Ensinos Médio e Superior. 2014. Tese (Doutorado em Educação Matemática) - Pontifícia Universidade Católica de São Paulo, São Paulo. [GS Search].

SANTOS, Adriana Tiago Castro dos. O ensino da função logarítmica por meio de uma sequência didática ao explorar suas representações com o uso do software GeoGebra. 2011. Dissertação (Mestrado em Educação) Pontifícia Universidade Católica de São Paulo, São Paulo, 2011. [GS Search].

SILVA, Rodrigo Sychocki da. $O$ uso de problemas no ensino e aprendizagem de funções exponenciais e logarítmicas na escola básica. Dissertação (mestrado) - Universidade Federal do Rio Grande do Sul, Instituto de Matemática, Programa de Pós-Graduação em Ensino de Matemática. 2012. Disponível em: http://www.lume.ufrgs.br/handle/10183/49422. [GS Search] 
SFARD, A. Operational Origins of Mathematical Objects and the quandary of reification - The case of function. In: DUBINSKY, E.; HAREL, G. (Ed.). The concept of function - Aspects of epistemology and pedagogy, MAA Notes 25, p. 59-84, 1992.

SIERPINSKA, A. On understanding the notion of function. In: DUBINSKY, E.;HAREL, G. (Ed.). The concept of function - Aspects of epistemology and pedagogy, MAA Notes 25, p. 25-58, 1992. 